\title{
Elevated pretreatment platelet distribution width and platelet count predict poor prognosis in nasopharyngeal carcinoma
}

\author{
XueCheng Xie ${ }^{1, *}$, XiaoChun Zeng ${ }^{1, *}$, SuJuan Cao ${ }^{1}$, XiaoMao Hu ${ }^{1}$, QiaoJing Shi ${ }^{1}$, \\ Dan $\mathrm{Li}^{1}$, ShiYuan Zhou ${ }^{2}$, Ping $\mathbf{G u}^{3}$ and ZhongShan Zhang ${ }^{1}$ \\ ${ }^{1}$ Department of Oncology, The Affiliated Hospital of XiangNan University, Chenzhou, China \\ ${ }^{2}$ Department of Nuclear Medicine, The Affiliated Hospital of XiangNan University, Chenzhou, China \\ ${ }^{3}$ Department of Child Healthcare, Chenzhou First People's Hospital, Chenzhou, China \\ "These authors have contributed equally to this work \\ Correspondence to: Ping Gu, email: guping0806@163.com \\ ZhongShan Zhang, email: zszhang01@126.com \\ Keywords: nasopharyngeal carcinoma; platelet distribution width; prognosis; overall survival \\ Received: July 31, $2017 \quad$ Accepted: October 28, $2017 \quad$ Published: November 20, 2017 \\ Copyright: Xie et al. This is an open-access article distributed under the terms of the Creative Commons Attribution License 3.0 \\ (CC BY 3.0), which permits unrestricted use, distribution, and reproduction in any medium, provided the original author and source \\ are credited.
}

\section{ABSTRACT}

Background: Previous studies have demonstrated that platelets play a multifaceted role in cancer progression and metastasis. However, the value of platelet indices for predicting survival in nasopharyngeal carcinoma (NPC) patients remains unknown. The aim of this study was to evaluate the predictive significance of platelet indices in NPC cases.

Materials and Methods: A total of 168 patients who were diagnosed with NPC between January 2011 and June 2012 were recruited. The optimal cut-off values for the platelet indices were determined using a receiver operating characteristic curve. The Kaplan-Meier method and Cox regression were used to evaluate the prognostic impact of the potential predictors.

Results: Of the 168 patients, high platelet distribution width (PDW) and platelet count (PLT) levels were observed in $81(48.21 \%)$ and $68(40.48 \%)$ of the patients, respectively. An increased PDW was associated with the depth of invasion (T stage, $P$ $=0.019$ ), lymph node metastasis ( $N$ stage, $P=0.026)$, and clinical stage $(P<0.001)$. Moreover, the survival analysis showed that the overall survival of the patients with a PDW $>16.3 \mathrm{fL}$ or platelet count $>266 \times 10^{9} / \mathrm{L}$ was associated with a poorer prognosis (both $P<0.001)$. In the multivariate Cox regression model, the PDW $(P<0.001)$, PLT $(P=0.001)$, T stage $(P<0.001), N$ stage $(P=0.006)$, clinical stage $(P=0.005)$, and Epstein-Barr virus DNA $(P=0.039)$ were independent prognostic factors for the overall survival.

Conclusions: The PDW and PLT are easily available via a routine blood test, and our study showed that the PDW and PLT could be prognostic predictors in NPC patients. However, further studies are required to confirm this conclusion.

\section{INTRODUCTION}

Nasopharyngeal carcinoma (NPC) is the most frequently diagnosed tumor originating in the nasopharynx. It exhibits a distinct endemic distribution, with a particularly high incidence in Southern China and its surrounding regions [1]. Radiotherapy, with or without chemotherapy, is the standard treatment for patients with NPCs, while the prognosis for patients with tumor-nodemetastasis (TNM) stages I and II is infusive [2]. Currently, TNM staging remains the gold standard for predicting the outcome of NPC [3]. However, even within the 
same staging category, there is variability in the patient outcomes because of the inability of the TNM system to reflect biological heterogeneity among the cancer cases [4]. Recent studies have reported a number of additional NPC prognostic markers, such as circulating Epstein-Barr virus (EBV) DNA loads [5], pretreatment serum lactate dehydrogenase [6], and microRNA signatures [7]. Due to the current limitations, such as detection difficulty, cost efficiency, and interlaboratory variability, the identification of appropriate and effective NPC prognostic markers is still of great value.

Multiple studies have suggested that platelets play a significant role in cancer progression and metastasis. For example, activated platelets promote cancer cell growth, aberrant angiogenesis, and invasion [8,9]. Some platelet indices, such as the platelet count (PLT), mean platelet volume (MPV), platelet distribution width (PDW), and platelet-lymphocyte ratio (PLR), can be easily tested and have been demonstrated to be related to the prognosis of various cancers, including non-small cell lung cancer, breast cancer, gastric cancer, colorectal cancer, pancreatic cancer, and laryngeal cancer [10-15].

The MPV shows the average size of the platelets in the bloodstream, but it does not reflect the microscopically observed changes in the platelet size. The PDW is calculated as the coefficient of variation in the MPV, and high PDW values show that the change in the MPV is greater than normal [16]. Recently, some studies have found that an elevated pretreatment PLT or PLR was significantly and independently associated with a poor overall survival (OS) in NPC patients $[17,18]$.

These abovementioned studies only evaluated one or two biomarkers, without considering others. Moreover, the prognostic values of the PDW and MPV in NPC have not yet been established. Overall, the clinical significance of the platelet indices in the prognosis of NPC still remains unclear. Thus, the aim of this analysis was to investigate the prognostic value of the platelet indices mentioned above for patients with NPC, and to evaluate the correlation between these potential prognostic predictors and the clinical-pathological parameters.

\section{RESULTS}

The patient characteristics are outlined in Table 1. Overall, there were $119(70.83 \%)$ male patients and 49 (29.17\%) female patients, and the median age at diagnosis was 49 years old (range 29-76). In terms of the staging system, 28 cases $(16.67 \%)$ were categorized as stage I or stage II, and 140 patients $(83.33 \%)$ were stage III or stage IV (including stage IVA and IVB). The median follow-up time for the current cohort was 65.2 months (range 11.477.2). Finally, there were 112 cancer-related deaths at the time of the last follow-up.
According to the ROC curve analysis, the optimum cut-off values of the PLT, MPV, PDW, and PLR for the 5 -year OS were $266 \times 10^{9} / \mathrm{L}$ (sensitivity $49.1 \%$, specificity $76.8 \%$ ), $10.6 \mathrm{fL}$ (sensitivity $67.0 \%$, specificity $76.8 \%$ ), $16.3 \mathrm{fL}$ (sensitivity $59.8 \%$, specificity $75.0 \%$ ), and 130.22 (sensitivity $78.6 \%$, specificity $55.4 \%$ ), respectively. The areas under the curve (AUCs) for the PLT, MPV, PDW, and PLR were 0.632 (95\% CI: 0.554-0.705, $\mathrm{P}=0.003)$, 0.713 (95\% CI: 0.638-0.780, P < 0.001), 0.707 (95\% CI: $0.631-0.774, \mathrm{P}<0.001)$, and 0.632 (95\% CI: 0.554-0.705, $\mathrm{P}=0.004$ ), respectively (Figure 1 and Table 2). Consistent with a previous report [5], we used 1500 copies $/ \mathrm{mL}$ as the cut-off value, and all of the patients were divided into either low $(<1500$ copies/mL) or high $(\geq 1500$ copies $/ \mathrm{mL})$ pretreatment EBV DNA groups.

The univariate Cox proportional hazards analyses revealed that the age at diagnosis (categorical variable), depth of invasion (T stage, T3-4 vs. T1-2), lymph node metastasis (N stage, N2-3 vs. N0-1), clinical stage (IIIIV vs. I-II), platelet count $(\times 109 / \mathrm{L})(>266$ vs. $\leq 266)$, MPV (fL) $(>10.6$ vs. $\leq 10.6)$, PDW (fL) $(>16.3$ vs. $\leq$ 16.3), PLR ( $>130.22$ vs. $\leq 130.22$ ), and EBV DNA (high vs. low) were significantly associated with the OS (Table 3 ). However, the other parameters were not found to be correlated with the OS. All of the factors with $\mathrm{P}$ values of less than 0.05 in the univariate analyses were included in the subsequent multivariate Cox proportional hazards models.

In the multivariate analyses, we demonstrated that the PDW (HR 2.362, 95\% CI: 1.554-3.590, P < 0.001), PLT (HR 2.017, 95\% CI: 1.329-3.060, P = 0.001), T stage (HR 2.768, 95\% CI: 1.603-4.779, P <0.001), N stage (HR 2.165, 95\% CI: 1.245-3.765, P =0.006), clinical stage (HR 9.534, 95\% CI: 1.998-45.498, P = 0.005), and EBV DNA (HR 1.619, 95\% CI: 1.024 $2.560, \mathrm{P}=0.039)$ were independent prognostic factors for NPC patients (Table 4).

The relationship between the PDW, PLT, and clinicopathological characteristics in NPC patients is shown in Table 1. There were no differences in the age distribution $(\mathrm{P}=0.120)$, gender $(\mathrm{P}=0.252)$, smoking history $(\mathrm{P}=0.615)$, body mass index $(\mathrm{P}=0.091)$, diabetes incidence $(P=0.290)$, family history of NPC $(P=0.735)$, KPS $(\mathrm{P}=0.176)$, undifferentiated carcinoma incidence $(\mathrm{P}=0.440), \operatorname{CCRT}(\mathrm{P}=0.519)$, IMRT $(\mathrm{P}=0.533)$, and EBV DNA $(\mathrm{P}=0.096)$ with regard to the PDW. However, the PDW was associated with the T stage $(\mathrm{P}=0.019), \mathrm{N}$ stage $(\mathrm{P}=0.026)$, and clinical stage $(\mathrm{P}<0.001)$. Moreover, none of the clinicopathological features were significantly associated with the PLT.

The 5-year OS rate in this cohort was $69.05 \%$, while the 5-year overall survival rates in those patients with $\mathrm{PDW} \leq 16.3 \mathrm{fL}$ and $\mathrm{PDW}>16.3 \mathrm{fL}$ were $86.21 \%$ and $50.62 \%$, respectively. The results of the KaplanMeier and log-rank tests showed that the OS of the NPC 
Table 1: Baseline characteristics of the patients according to the PDW and PLT

\begin{tabular}{|c|c|c|c|c|c|c|c|}
\hline \multirow{2}{*}{ Variables } & \multirow{2}{*}{ Total $n=168$} & \multicolumn{2}{|c|}{ PDW (fL) } & \multirow{2}{*}{$P$} & \multicolumn{2}{|c|}{ PLT $\left(\times 10^{9} / \mathrm{L}\right)$} & \multirow{2}{*}{$P$} \\
\hline & & $\leq 16.3(\mathrm{n}=87)$ & $>16.3(n=81)$ & & $\leq 266(n=100)$ & $>266(n=68)$ & \\
\hline Age (years) & & & & 0.120 & & & 0.176 \\
\hline$<60$ & 146 & 79 & 67 & & 84 & 62 & \\
\hline$\geq 60$ & 22 & 8 & 14 & & 16 & 6 & \\
\hline Gender & & & & 0.252 & & & 0.773 \\
\hline Male & 119 & 65 & 54 & & 70 & 49 & \\
\hline Female & 49 & 22 & 27 & & 30 & 19 & \\
\hline Smoking & & & & 0.615 & & & 0.485 \\
\hline Yes & 59 & 29 & 30 & & 33 & 26 & \\
\hline No & 109 & 58 & 51 & & 67 & 42 & \\
\hline $\mathrm{BMI}(\mathrm{kg} / \mathrm{m} 2)$ & & & & 0.091 & & & 0.491 \\
\hline$>23.7$ & 82 & 37 & 45 & & 51 & 31 & \\
\hline$\leq 23.7$ & 86 & 50 & 36 & & 49 & 37 & \\
\hline Diabetes & & & & 0.290 & & & 0.053 \\
\hline Yes & 11 & 4 & 7 & & 3 & 8 & \\
\hline No & 157 & 83 & 74 & & 97 & 60 & \\
\hline $\begin{array}{l}\text { Family history } \\
\text { of NPC }\end{array}$ & & & & 0.735 & & & 0.245 \\
\hline Yes & 18 & 10 & 8 & & 13 & 5 & \\
\hline No & 150 & 77 & 73 & & 87 & 63 & \\
\hline KPS & & & & 0.176 & & & 0.069 \\
\hline$\leq 80$ & 76 & 35 & 41 & & 51 & 25 & \\
\hline$>80$ & 92 & 52 & 40 & & 49 & 43 & \\
\hline $\begin{array}{l}\text { Undifferentiated } \\
\text { carcinoma }\end{array}$ & & & & 0.440 & & & 0.209 \\
\hline Yes & 84 & 46 & 38 & & 54 & 30 & \\
\hline No & 84 & 41 & 43 & & 46 & 38 & \\
\hline T stage & & & & 0.019 & & & 0.287 \\
\hline $\mathrm{T} 1-2$ & 80 & 49 & 31 & & 51 & 29 & \\
\hline T3-4 & 88 & 38 & 50 & & 49 & 39 & \\
\hline $\mathrm{N}$ stage & & & & 0.026 & & & 0.574 \\
\hline N0-1 & 60 & 38 & 22 & & 34 & 26 & \\
\hline $\mathrm{N} 2-3$ & 108 & 49 & 59 & & 66 & 42 & \\
\hline Clinical stage & & & & $<0.001$ & & & 0.574 \\
\hline I-II & 28 & 24 & 4 & & 18 & 10 & \\
\hline III-IVB & 140 & 63 & 77 & & 82 & 58 & \\
\hline CCRT & & & & 0.519 & & & 0.086 \\
\hline
\end{tabular}

(Continued) 


\begin{tabular}{|c|c|c|c|c|c|c|c|}
\hline \multirow{2}{*}{ Variables } & \multirow{2}{*}{ Total $n=168$} & \multicolumn{2}{|c|}{ PDW (fL) } & \multirow{2}{*}{$\boldsymbol{P}$} & \multicolumn{2}{|c|}{ PLT $\left(\times 10^{9} / \mathrm{L}\right)$} & \multirow{2}{*}{$P$} \\
\hline & & $\leq 16.3(n=87)$ & $>16.3(n=81)$ & & $\leq 266(n=100)$ & $>266(n=68)$ & \\
\hline Yes & 116 & 62 & 54 & & 64 & 52 & \\
\hline No & 52 & 25 & 27 & & 36 & 16 & \\
\hline IMRT & & & & 0.533 & & & 0.147 \\
\hline Yes & 126 & 67 & 59 & & 79 & 47 & \\
\hline No & 42 & 20 & 22 & & 21 & 21 & \\
\hline EBV DNA & & & & 0.096 & & & 0.194 \\
\hline High & 114 & 54 & 60 & & 64 & 50 & \\
\hline low & 54 & 33 & 21 & & 36 & 18 & \\
\hline
\end{tabular}

Abbreviations: PDW, platelet distribution width; PLT, platelet count; BMI, Body mass index; UC, Undifferentiated carcinoma; KPS, Karnofsky performance score; CCRT, concurrent chemoradiotherapy; IMRT, intensity-modulated radiotherapy; EBV: Epstein-Barr.

patients with PDWs greater than $16.3 \mathrm{fL}$ was shorter than that of the patients with PDWs less than or equal to 16.3 $\mathrm{fL}(\mathrm{P}<0.001)$. In addition, the OS of those patients with an increased PLT was also significantly shorter than in those with lower PLT levels $(\mathrm{P}<0.001)$. Additionally, an adjusted Cox proportional hazard survival curve was used to investigate the effects of the PDW and PLT on survival. The outcomes were the same as those obtained while using the Kaplan-Meier method (Figure 2).

\section{DISCUSSION}

To the best of our knowledge, this is the first study to investigate the prognostic value of the pretreatment PDW in NPC patients, and the first to systematically evaluate the relationships between the PLT, MPV, PDW, PLR, and the prognosis of NPC. This study revealed that a PDW with a cut-off $16.3 \mathrm{fL}$ and a PLT with a cut-off

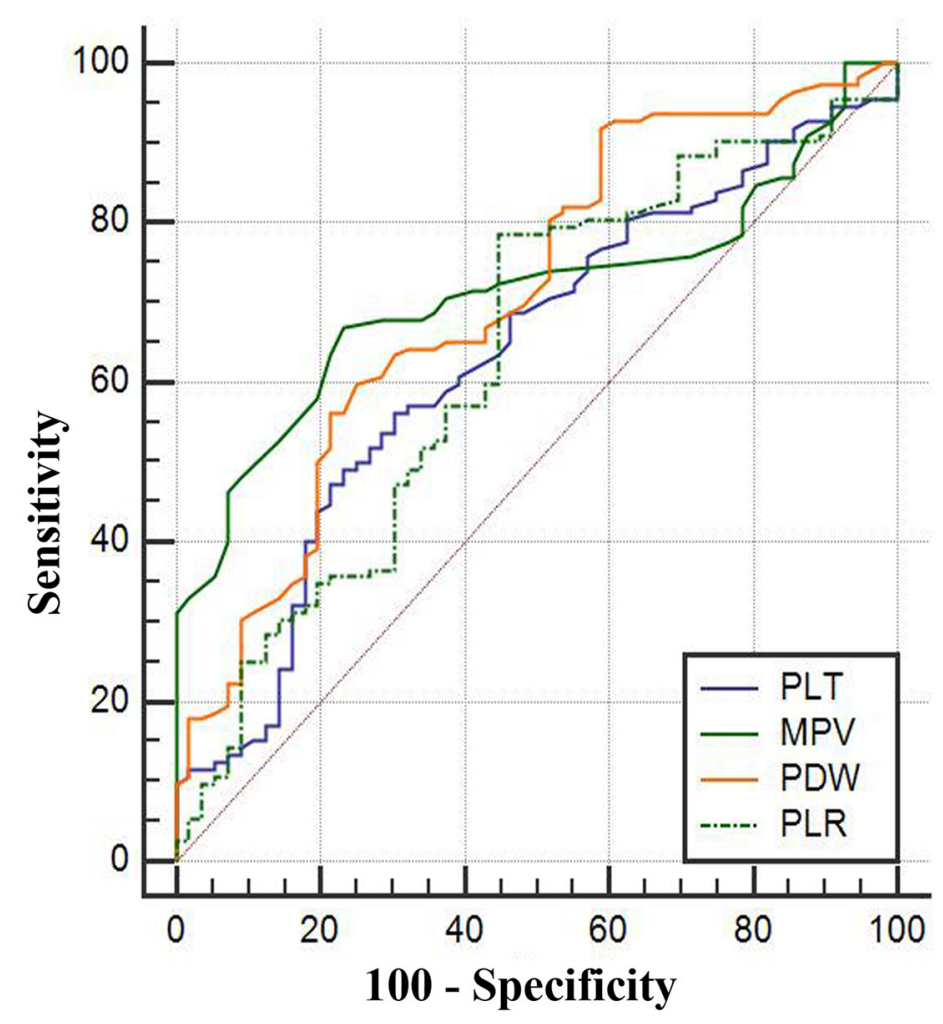

Figure 1: The ROC curves grouped by PLT, MPV, PDW and PLR. ROC, receiver operating characteristic. Notes: The blue line represents PLT, the green line MPV, and the orange line PDW, and the imaginary line PLR. 
Table 2: Receiver operating characteristic curve analyses showing the utility of platelet indices for NPC

\begin{tabular}{lcccccc}
\hline Platelet indices & Cut-off values & AUC & Sensibility & Specificity & 95\% CI & P-value \\
\hline PLT $(\times 109 / \mathrm{L})$ & 266 & 0.632 & 49.1 & 76.8 & $0.554-0.705$ & 0.003 \\
MPV (fL) & 10.6 & 0.713 & 67.0 & 76.8 & $0.638-0.780$ & $<0.001$ \\
PDW (fL) & 16.3 & 0.707 & 59.8 & 75.0 & $0.631-0.774$ & $<0.001$ \\
PLR & 130.22 & 0.632 & 78.6 & 55.4 & $0.554-0.705$ & 0.004 \\
\hline
\end{tabular}

Abbreviations: see Table 1.

Table 3: Result of the univariate analysis of overall survival in NPC patients

\begin{tabular}{|c|c|c|c|}
\hline Characteristic & Hazard ratio & $95 \% \mathrm{CI}$ & P-value \\
\hline Sex (male vs. female) & 1.435 & $0.925-2.227$ & 0.107 \\
\hline Age ( $\geq 60$ vs. $<60$ years $)$ & 1.719 & $1.035-2.852$ & 0.036 \\
\hline Smoking (yes vs. no) & 1.448 & $0.985-2.129$ & 0.060 \\
\hline $\begin{array}{l}\text { BMI }(\mathrm{kg} / \mathrm{m} 2)(>23.7 \mathrm{vs} . \\
\leq 23.7)\end{array}$ & 1.335 & $0.917-1.943$ & 0.132 \\
\hline Diabetes (yes vs. no) & 1.767 & $0.856-3.647$ & 0.124 \\
\hline $\begin{array}{l}\text { Family history of NPC (yes } \\
\text { vs. no) }\end{array}$ & 0.986 & $0.563-1.728$ & 0.962 \\
\hline KPS $(\leq 80$ vs. $>80)$ & 1.168 & $0.805-1.696$ & 0.414 \\
\hline $\begin{array}{l}\text { Undifferentiated cancer (yes } \\
\text { vs. no) }\end{array}$ & 0.948 & $0.652-1.380$ & 0.782 \\
\hline T stage(T3-4 vs. T1-2) & 4.786 & $2.963-7.728$ & $<0.001$ \\
\hline $\mathrm{N}$ stage (N2-3 vs. $\mathrm{N} 0-1)$ & 4.099 & $2.536-6.651$ & $<0.001$ \\
\hline $\begin{array}{l}\text { Clinical stage (III-IVB) vs. } \\
\text { (I-II) }\end{array}$ & 43.441 & $10.284-183.507$ & $<0.001$ \\
\hline CCRT (no vs. yes) & 0.936 & $0.620-1.413$ & 0.753 \\
\hline IMRT (no vs. yes) & 1.292 & $0.839-1.988$ & 0.245 \\
\hline $\begin{array}{l}\text { PLT }(>266 \text { vs. } \leq 266) \\
(\times 109 / \text { L })\end{array}$ & 1.979 & $1.361-2.877$ & $<0.001$ \\
\hline MPV (>10.6vs. $\leq 10.6) \mathrm{fL}$ & 0.385 & $0.257-0.577$ & $<0.001$ \\
\hline PDW (>16.3 vs. $\leq 16.3) \mathrm{fL}$ & 2.986 & $2.030-4.394$ & $<0.001$ \\
\hline PLR (>130.22 vs. $\leq 130.22)$ & 2.890 & $1.835-4.553$ & $<0.001$ \\
\hline $\begin{array}{l}\text { EBV DNA (high vs. low) } \\
\text { (copies } / \mathrm{mL} \text { ) }\end{array}$ & 2.192 & $1.418-3.388$ & $<0.001$ \\
\hline
\end{tabular}

Abbreviations: see Table 1.

$266 \times 10^{9} / \mathrm{L}$ had independent prognostic significances for the OS in NPC patients.

Platelets, a blood component, have been generally recognized as mediating tumor cell growth, metastasis, and angiogenesis. Activated platelets are capable of interacting with cancer cells through paracrine signaling or direct contact, consequently promoting tumor cell growth and survival [19]. An elevated blood platelet count is a common phenomenon in many kinds of malignancies and is linked to reduced survival in patients with various tumor types, including lung, breast, gastric, colorectal, pancreatic, brain, endometrial, and ovarian cancer. Although these results somewhat overlapped with those of the present study, our present study confirmed the key role of activated platelets in NPC using a simple platelet parameter. These data are also in accordance with the 
Table 4: Multivariate Cox proportional hazards regression analysis

\begin{tabular}{lccc}
\hline Characteristic & Hazard ratio & $\mathbf{9 5 \%}$ CI & P-value \\
\hline Age $(\geq 60$ vs. $<60$ years) & 1.696 & $0.927-3.104$ & 0.087 \\
T stage(T3-4 vs. T1-2) & 2.768 & $1.603-4.779$ & $<0.001$ \\
N stage (N2-3 vs. N0-1) & 2.165 & $1.245-3.765$ & 0.006 \\
Clinical stage (III-IVB) vs. & 9.534 & $1.998-45.498$ & 0.005 \\
$\begin{array}{l}\text { (I-II) } \\
\text { PLT (>266 vs. } \leq 266)\end{array}$ & & $1.329-3.060$ & 0.001 \\
$(\times 109 /$ L) & 2.017 & $0.404-1.028$ & 0.065 \\
MPV $(>10.6 v s . \leq 10.6)$ fL & 0.645 & $1.554-3.590$ & $<0.001$ \\
PDW (>16.3 vs. $\leq 16.3)$ fL & 2.362 & $0.933-2.487$ & 0.092 \\
PLR $(>130.22$ vs. $\leq 130.22)$ & 1.523 & $1.024-2.560$ & 0.039 \\
EBV DNA (high vs. low) & 1.619 & & \\
(copies/mL) & &
\end{tabular}

Abbreviations: see Table 1.
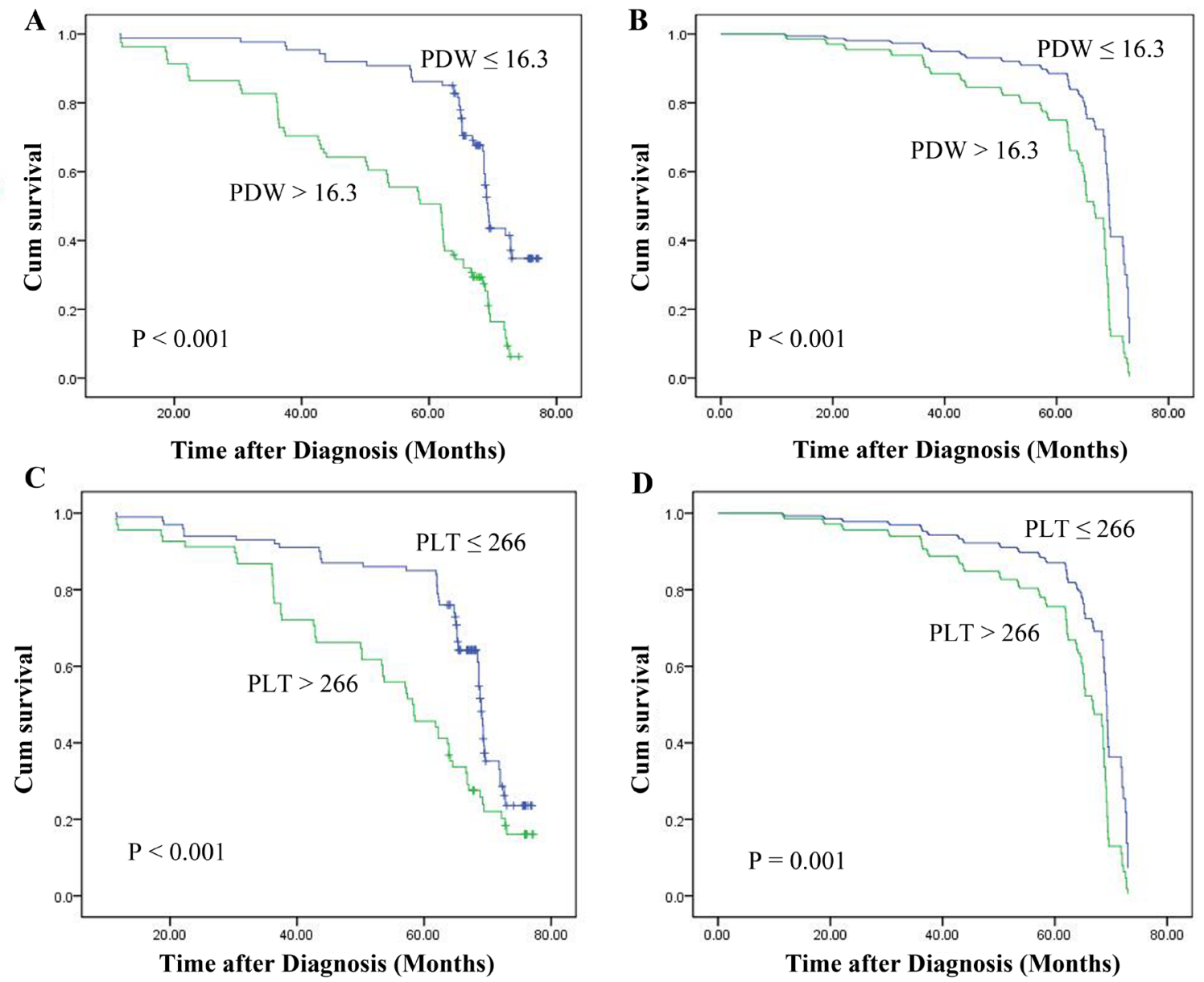

Figure 2: Kaplan-Meier survival curves for NPC patients according to whether they show high or lower (A) PDW and (C) PLT levels. Multivariate Cox survival curves for NPC patients according to whether they show high or lower (B) PDW and (D) PLT levels. 
present knowledge that antiplatelet therapy is considered to be one portion of adjuvant cancer therapy [8].

It is now generally recognized that the PDW can not only measure platelet volume heterogeneity, but also reflect platelet activity. Recently, one study reported that a reduced PDW is an unfavorable predictive factor for nonsmall cell lung cancer patient survival [13]. Contrarily, an elevated PDW has been demonstrated to have a poor prognostic impact in melanoma [20], thyroid cancer [21], colorectal cancer [12], and laryngeal cancer [11]. However, the clinical value of the PDW has not yet been reported in NPC patients. Consistent with most studies, our results showed that an increased PDW was not only associated with the $\mathrm{T}$ stage, $\mathrm{N}$ stage, and clinical stage, but also significantly associated with a poorer OS in NPC patients. Moreover, an elevated PDW was an independent prognostic index for the OS in NPC patients.

New study has demonstrated that a high pretreatment MPV level in invasive breast cancer patients is a potential predictive factor and significant independent prognostic factor [14]. The study conducted by Omar et al. [22] reported that an increased MPV level may be used as a prognostic biomarker to estimate a poor OS in patients with lung cancer. However, the researchers found that the MPV levels were significantly increased in those patients with gastric ulcers and in the control subjects when compared with the gastric cancer patients [23]. This result seems to suggest that the MPV is a protective factor in gastric cancer. Moreover, this retrospective cohort study is the first study to investigate the prognostic value of pretreatment MPV levels in NPC patients. The results revealed that those patients with high MPV levels had 0.645 times the risk of death when compared to those with a low MPV levels, albeit the difference was not statistically significant after the multivariate analysis.

A previous study showed that elevated PLR values were associated with poor cancer-specific survival, OS, and distant metastasis free survival in patients with NPC [18]. In this study, the results of the multivariate analysis revealed that those patients with high PLR levels had 1.52 times the risk of death when compared to those with low PLR levels; however, the difference was not statistically significant $(\mathrm{P}>0.092)$. The discrepancies above may be attributed to the different tumor tissues, different sample sizes, and variability in the measurement methods. Of course, there is the fact that we have additionally adjusted for some potential prognostic factors, including the PLT and PDW.

At present, the biological mechanisms underlying the correlation between the PDW, PLT, and tumorigenesis or progression in NPC remains poorly understood. The platelet volume is determined during both megakaryopoiesis and thrombopoiesis. In megakaryocytic maturation, the platelet production and platelet size can be modulated by cytokines, such as interleukin-6 (IL-
6), the granulocyte colony stimulating factor, and the macrophage colony stimulating factor [24]. In addition, the tumor-associated production of the granulocytemacrophage colony stimulating factor or thrombopoietin mediated by IL- 6 is considered to be responsible for the increase in the PLT observed in cancer patients [25]. There is consistent evidence that IL- 6 is overexpressed in EBV-infected nasopharyngeal epithelial cancer cells [26]. By activating the IL-6-associated transcription factors (nuclear factor kappa-light-chain-enhancer of activated B cells and signal transducer and activator of transcription 3 ), the enhanced circulating IL-6 not only contributes to NPC's proliferative properties but also mediates platelet generation. Furthermore, elevated platelet levels promote cancer progression and metastasis by protecting the circulating tumor cells from immune surveillance and death [27]. Another reasonable mechanism is that platelets facilitate a hypercoagulable state in cancer. The increased number of platelets produces a procoagulant microenvironment that enables the cancer cells to cover themselves with platelets and escape the host's immune system [28].

There were some study limitations that should be addressed. First, our study may have been restricted by its retrospective design. Second, the number of subjects included in our study was relatively small, and the power of the statistical analysis was relatively weak; therefore, larger studies are warranted to validate our findings. Finally, all of the included studies were from Chinese populations; consequently, the conclusion might be limited to East Asian individuals.

In summary, the current study results suggest that the PDW and PLT could be new independent prognostic factors in NPC patients. However, additional investigations are warranted to fully understand the potential mechanism. These easily measured and inexpensive biomarkers may be used as practical predictors in daily clinical practice in the future.

\section{MATERIALS AND METHODS}

\section{Patient recruitment and data collection}

A total of 168 NPC patients were admitted to the Department of Oncology of the Affiliated Hospital of XiangNan University between January 2011 and June 2012. All of the included patients met the following criteria: (1) histological confirmation of NPC and no previous anticancer treatment; (2) no distant metastasis; (3) had received complete blood differential count records within 3 days prior to treatment; (4) available clinical information. The exclusion criteria were as follows: (1) Karnofsky Performance Scale (KPS) score < 70; (2) had other previously treated and/or synchronous malignancies; (3) the presence of a concomitant disease that can affect the platelet count, including severe hypertension, 
autoimmune disease, inflammation, liver cirrhosis, splenic disease, and a history of blood transfusion.

The pretreatment hematological parameters were measured via a Beckman Coulter LH750 automated analyzer (Beckman Coulter, California, USA). The EBV DNA concentrations were obtained using a quantitative polymerase chain reaction (DA 7600; Da-an, Zhongshan, China) before treatment, as previously reported [29].

This study was approved by the Institutional Review Board of the Affiliated Hospital of XiangNan University.

\section{Staging, treatment, and follow-up}

All of the patients were reassigned based on the 7th Edition of the American Joint Committee on Cancer (AJCC) cancer staging system for NPC as assessed via the compilation of the magnetic resonance imaging, chest radiograph, abdominal ultrasonography, whole-body bone scanning, and/or positron emission tomography-computed tomography results.

The treatment strategies for all of the patients were based on the National Comprehensive Cancer Network Guidelines. All of the patients received definitive radiotherapy (RT) using three-dimensional conformal RT (3D-CRT) and intensity-modulated RT (IMRT) techniques. Those patients with stage I-II malignancies were treated by RT alone or with concurrent chemoradiotherapy (CCRT). Those patients with stage III-IVB malignancies were treated with CCRT with or without induction/ adjuvant chemotherapy. The CCRT regimen was the use of $30 \mathrm{mg} / \mathrm{m}^{2}$ of cisplatin every week for 6-7 cycles during the RT period. The regimen for the induction/adjuvant chemotherapy included cisplatin $\left(75 \mathrm{mg} / \mathrm{m}^{2}\right.$ on day 1) and 5-fluorouracil $\left(1,000 \mathrm{mg} / \mathrm{m}^{2}\right.$ via a 96 -hour continuous infusion from days 2-5) administrated every 21 days for 2-3 cycles.

After completing treatment, the patients were followed up every three months for the first three years, with the intervals gradually increasing to 6-12 months after three years. The last follow-up date was June 30, 2017. The overall survival (OS) was calculated from the date of the diagnosis to the date of death or the last followup. The median follow-up time was 65.2 months.

\section{Statistical analysis}

The statistical analysis was performed using the Statistical Program for Social Sciences (SPSS) software, version 16.0 (SPSS Inc., Chicago, IL, USA). The optimal cut-off values of the platelet indices were determined by using a receiver operating characteristic (ROC) curve. The univariate and multivariate survival analyses were determined using the Cox proportional hazards model. The correlations between the potential prognostic predictors and the clinicopathological variables were evaluated via the chi-squared test. The Kaplan-Meier method and the corresponding log rank test were used for the survival analyses of the categorical variables. All of the tests were two-tailed, and the level of significance was $\mathrm{P}<0.05$.

\section{Author contributions}

XC Xie and XC Zeng mainly participated in literature search, study design, writing and critical revision. SJ Cao, XM Hu, QJ S, D Li and SY Zhou mainly participated in data collection, data analysis and data interpretation. P Gu and ZS Zhang contributed to the technical and material support. All authors read and approved the final manuscript.

\section{CONFLICTS OF INTEREST}

None of the authors have any conflicts of interest to declare.

\section{FUNDING}

This study was funded by the project of XiangNan University (2015XB17).

\section{REFERENCES}

1. Torre LA, Bray F, Siegel RL, Ferlay J, Lortet-Tieulent J, Jemal A. Global cancer statistics, 2012. CA Cancer J Clin. 2015; 65: 87-108. https://doi.org/10.3322/caac.21262.

2. Maingon $\mathrm{P}$, Blanchard $\mathrm{P}$, Bidault $\mathrm{F}$, Calmels L. [Radiotherapy for nasopharyngeal carcinoma]. [Article in French]. Cancer Radiother. 2016; 20: S104-9. https://doi. org/10.1016/j.canrad.2016.07.031.

3. Lee AW, Ma BB, Ng WT, Chan AT. Management of nasopharyngeal carcinoma: current practice and future perspective. J Clin Oncol. 2015; 33: 3356-64. https://doi. org/10.1200/jco.2015.60.9347.

4. Chua ML, Wee JT, Hui EP, Chan AT. Nasopharyngeal carcinoma. Lancet. 2016; 387: 1012-24. https://doi. org/10.1016/s0140-6736(15)00055-0.

5. Lin JC, Wang WY, Chen KY, Wei YH, Liang WM, Jan JS, Jiang RS. Quantification of plasma Epstein-Barr virus DNA in patients with advanced nasopharyngeal carcinoma. N Engl J Med. 2004; 350: 2461-70. https://doi.og/10.1056/ NEJMoa032260.

6. Wan XB, Wei L, Li H, Dong M, Lin Q, Ma XK, Huang PY, Wen JY, Li X, Chen J, Ruan DY, Lin ZX, Chen ZH, et al. High pretreatment serum lactate dehydrogenase level correlates with disease relapse and predicts an inferior outcome in locally advanced nasopharyngeal carcinoma. Eur J Cancer. 2013; 49: 2356-64. https://doi.org/10.1016/j. ejca.2013.03.008.

7. Liu N, Chen NY, Cui RX, Li WF, Li Y, Wei RR, Zhang MY, Sun Y, Huang BJ, Chen M, He QM, Jiang N, Chen 
L, et al. Prognostic value of a microRNA signature in nasopharyngeal carcinoma: a microRNA expression analysis. Lancet Oncol. 2012; 13: 633-41. https://doi. org/10.1016/s1470-2045(12)70102-X.

8. Mezouar S, Frere C, Darbousset R, Mege D, Crescence L, Dignat-George F, Panicot-Dubois L, Dubois C. Role of platelets in cancer and cancer-associated thrombosis: experimental and clinical evidences. Thromb Res. 2016; 139: 65-76. https://doi.org/10.1016/j.thromres.2016.01.006.

9. Buergy D, Wenz F, Groden C, Brockmann MA. Tumorplatelet interaction in solid tumors. Int J Cancer. 2012; 130: 2747-60. https://doi.org/10.1002/ijc.27441.

10. Zhang X, Cui MM, Fu S, Li LL, Liu YS, Liu ZP, Liu T, Wang RT, Yu KJ. Platelet distribution width correlates with prognosis of gastric cancer. Oncotarget. 2017; 8: 20213-9. https://doi.org/10.18632/oncotarget.15561.

11. Zhang H, Liu L, Fu S, Liu YS, Wang C, Liu T, Liu ZP, Wang RT, Yu KJ. Higher platelet distribution width predicts poor prognosis in laryngeal cancer. Oncotarget. 2017; 8: 48138-44. https://doi.org/10.18632/oncotarget.18306.

12. Song X, Zhu H, Pei Q, Tan F, Li C, Zhou Z, Zhou Y, Yu N, Li Y, Pei H. Significance of inflammation-based indices in the prognosis of patients with non-metastatic colorectal cancer. Oncotarget. 2017; 8: 45178-89. https:// doi.org/10.18632/oncotarget.16774.

13. Cui MM, Li N, Liu X, Yun ZY, Niu Y, Zhang Y, Gao B, Liu T, Wang RT. Platelet distribution width correlates with prognosis of non-small cell lung cancer. Sci Rep. 2017; 7: 3456. https://doi.org/10.1038/s41598-017-03772-Z.

14. Gu M, Zhai Z, Huang L, Zheng W, Zhou Y, Zhu R, Shen F, Yuan C. Pre-treatment mean platelet volume associates with worse clinicopathologic features and prognosis of patients with invasive breast cancer. Breast Cancer. 2016; 23: 75260. https://doi.org/10.1007/s12282-015-0635-6.

15. Liu P, Zhu Y, Liu L. Elevated pretreatment plasma D-dimer levels and platelet counts predict poor prognosis in pancreatic adenocarcinoma. Onco Targets Ther. 2015; 8: 1335-40. https://doi.org/10.2147/ott.s82329.

16. Thompson CB, Jakubowski JA. The pathophysiology and clinical relevance of platelet heterogeneity. Blood. 1988; 72: 1-8.

17. Chen YP, Chen C, Mai ZY, Gao J, Shen LJ, Zhao BC, Chen MK, Chen G, Yan F, Huang TY, Xia YF. Pretreatment platelet count as a predictor for survival and distant metastasis in nasopharyngeal carcinoma patients. Oncol Lett. 2015; 9: 1458-66. https://doi.org/10.3892/ ol.2015.2872.

18. Jiang R, Zou X, Hu W, Fan YY, Yan Y, Zhang MX, You R, Sun R, Luo DH, Chen QY, Huang PY, Hua YJ, Guo L, et al. The elevated pretreatment platelet-to-lymphocyte ratio predicts poor outcome in nasopharyngeal carcinoma patients. Tumour Biol. 2015; 36: 7775-87. https://doi. org/10.1007/s13277-015-3505-0.
19. Sharma D, Brummel-Ziedins KE, Bouchard BA, Holmes CE. Platelets in tumor progression: a host factor that offers multiple potential targets in the treatment of cancer. J Cell Physiol. 2014; 229: 1005-15. https://doi.org/10.1002/ jcp.24539.

20. Li N, Diao Z, Huang X, Niu Y, Liu T, Liu ZP, Wang RT, Yu KJ. Increased platelet distribution width predicts poor prognosis in melanoma patients. Sci Rep. 2017; 7: 2970. https://doi.org/10.1038/s41598-017-03212-y.

21. Yu YJ, Li N, Yun ZY, Niu Y, Xu JJ, Liu ZP, Liu T, Wang RT, Yu KJ. Preoperative mean platelet volume and platelet distribution associated with thyroid cancer. Neoplasma. 2017; 64: 594-8. https://doi.org/10.4149/neo_2017_414.

22. Omar M, Tanriverdi O, Cokmert S, Oktay E, Yersal O, Pilanci KN, Menekse S, Kocar M, Sen CA, Ordu C, Goksel G, Meydan N, Barutca S. Role of increased mean platelet volume (MPV) and decreased MPV/platelet count ratio as poor prognostic factors in lung cancer. Clin Respir J. 2016. https://doi.org/10.1111/crj.12605.

23. Yun ZY, Li N, Zhang X, Zhang H, Bu Y, Sun Y, Liu T, Wang RT, Yu KJ. Mean platelet volume, platelet distribution width and carcinoembryonic antigen to discriminate gastric cancer from gastric ulcer. Oncotarget. 2017; 8: 62600-5. https://doi. org/10.18632/oncotarget.15898.

24. Kaushansky K. Growth factors and hematopoietic cell fate. A new feature: controversies in hematology. Blood. 1998; 92: 345-4.

25. Kaser A, Brandacher G, Steurer W, Kaser S, Offner FA, Zoller H, Theurl I, Widder W, Molnar C, Ludwiczek O, Atkins MB, Mier JW, Tilg H. Interleukin-6 stimulates thrombopoiesis through thrombopoietin: role in inflammatory thrombocytosis. Blood. 2001; 98: 2720-5.

26. Zhang G, Tsang CM, Deng W, Yip YL, Lui VW, Wong SC, Cheung AL, Hau PM, Zeng M, Lung ML, Chen H, Lo KW, Takada K, et al. Enhanced IL-6/IL-6R signaling promotes growth and malignant properties in EBV-infected premalignant and cancerous nasopharyngeal epithelial cells. PLoS One. 2013; 8: e62284. https://doi.org/10.1371/journal. pone. 0062284 .

27. Meikle CK, Kelly CA, Garg P, Wuescher LM, Ali RA, Worth RG. Cancer and thrombosis: the platelet perspective. Front Cell Dev Biol. 2016; 4: 147. https://doi.org/10.3389/ fcell.2016.00147.

28. Santilli F, Boccatonda A, Davi G. Aspirin, platelets, and cancer: the point of view of the internist. Eur J Intern Med. 2016; 34: 11-20. https://doi.org/10.1016/j.ejim.2016.06.004.

29. Shao JY, Li YH, Gao HY, Wu QL, Cui NJ, Zhang L, Cheng G, Hu LF, Ernberg I, Zeng YX. Comparison of plasma Epstein-Barr virus (EBV) DNA levels and serum EBV immunoglobulin $\mathrm{A} /$ virus capsid antigen antibody titers in patients with nasopharyngeal carcinoma. Cancer. 2004; 100: 1162-70. https://doi.org/10.1002/cncr.20099. 